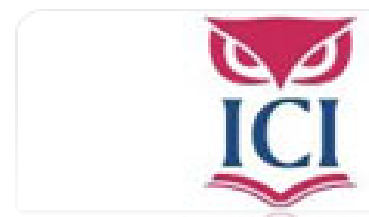

IUS. Revista del Instituto de Ciencias Jurídicas de Puebla A.C.

ISSN: $1870-2147$

revista.ius@hotmail.com

Instituto de Ciencias Jurídicas de Puebla A. C.

México

Saavedra López, Modesto

La crítica del derecho como paradigma de la filosofía jurídica

IUS. Revista del Instituto de Ciencias Jurídicas de Puebla A.C., núm. 22, 2008, pp. 322-331

Instituto de Ciencias Jurídicas de Puebla A. C.

Puebla, México 
Elautorseplanteasipuedehablarsede unafilosofíadelderechoycuálmerece la pena cultivar. Para responder estas cuestiones reseña dos posiciones: el iusnaturalismoyeliuspositivismo,para llegar a la conclusión de que el punto de vista de la crítica, el principio moral que la anima, puede estar reflejado, aunque sólo sea de manera abstracta o fragmentaria, en el sistema jurídico criticado

\section{La crítica del derecho como paradigma de la filosofía jurídica}

\section{Modesto Saavedra López}

E n una entrega anterior (IUS, No. 20, 2007, pp. 325 y ss) intentábamos dar respuesta a la pregunta ¿puede hablarse de una filosofía del derecho?, y bajo ese epígrafe abordábamos algunos aspectos que permiten aclarar al ámbito temático de este campo del saber, es decir, de qué se ocupa este tipo de reflexión y qué es lo que les corresponde enseñar a los profesores de una disciplina con ese título en la formación de los juristas. En tal sentido, decíamos que el objeto de la filosofía del derecho es el derecho en su conjunto y todo lo que tiene que ver con él, fijándose sobre

\footnotetext{
* Doctor en derecho, catedrático en filosofía, coordinó la presente entrega de IUS.
}

todo en sus aspectos más genéricos y más profundos. Su objetivo es averiguar el significado del derecho como tal, explicando sus fines y funciones en la vida humana y social, sus condicionamientos económicos, culturales y políticos, y sus relaciones con otras estructuras y prácticas sociales. Pretende, igualmente, analizar su estructura como norma y sistema normativo y sus conceptos básicos y generales, a fin de proporcionar el máximo rigor teórico al pensamiento jurídico y la mayor consistencia y solidez a la práctica profesional de abogados y juristas. Dedicada a reflexionar sobre estos temas, la filosofía del derecho se convierte en una “ontología” jurídica o teoría del derecho, porque se ocupa de lo que el derecho es, de cómo se presenta en la realidad y cómo funciona. $Y$ ello con independencia de que la reflexión teórica puede tener un carácter más o menos especulativo y "metafísico", más o menos sociológico, o quedarse en un análisis puramente lingüístico y formal, dependiendo del interés y del punto de vista adoptado por el filósofo correspondiente.

Pero además de presentarse como ontología jurídica, decíamos también que la filosofía del derecho puede adoptar otra vestimenta y aparecer como una "deontología” jurídica, es decir, como una teoría de la justicia, de los valores y de la legitimidad del 
derecho. Deontología: o sea, teoría o doctrina acerca del deber ser, más allá de lo que es o existe como tal. En este sentido, la filosofía jurídica trata de dar respuesta a una serie de preguntas fundamentales que son ineludibles en el campo de la reflexión teórica y que reclaman la atención sobre todo en el campo de la praxis jurídica y política. Se trata nada más y nada menos que de discurrir sobre la eterna y controvertida cuestión de qué es lo justo, de qué ideales deben inspirar la labor del legislador y de qué actitud debe adoptar el ciudadano ante el poder que se ejerce mediante las formas del derecho.

Finalmente, la filosofía del derecho puede adoptar también la forma de "epistemología" jurídica, o sea, de teoría de la ciencia jurídica, cuyo objeto de reflexión no es otro que el problema del conocimiento del derecho y de los valores que lo inspiran. 0 sea, la filosofía del derecho afronta el saber jurídico y la especulación sobre la justicia precisamente como un problema, reflexionando sobre sus posibilidades y sus límites, sobre sus métodos y garantías. Y, así, intenta contestar a preguntas como la de cuánto hay de racionalidad en la especulación teórica y filosófica, cuáles son los procedimientos de investigación y construcción que debe emplear la ciencia jurídica para ser tal, o cuáles son los criterios de objetividad, si es que los hay, que garantizan la validez universal del discurso moral.
No cabe duda de que, dedicada a reflexionar sobre todos estos temas, puede hablarse, efectivamente, de una filosofía del derecho. Y no deben caber dudas sobre su importancia en la formación de los juristas. Efectivamente, no bastan las ciencias jurídicas para que éstos consigan el dominio intelectual y moral del derecho que los convierta en expertos dedicados profesionalmente a resolver problemas de la convivencia social manejando la ley como instrumento de mediación y de control. Las ciencias jurídicas aportan conocimientos, evidentemente: el conocimiento del derecho en vigor, el que viene dado a la experiencia y que hay que aceptar y asumir dogmáticamente porque el principio de legalidad es inexcusable en una sociedad mínimamente compleja y funcional. Pero las ciencias jurídicas tienen una serie de presupuestos que ellas no sacan a la luz ni toman normalmente como objeto de reflexión: son los presupuestos a los que hemos hecho referencia como objeto de la filosofía jurídica, y que, cuando son abordados eventualmente por alguna de las ciencias jurídicas, hacen que ésta se aproxime a aquélla y adquiera la profundidad y la riqueza que no tiene cuando se limita a ser meramente empírica y descriptiva: desde el concepto del derecho subjetivo hasta el alcance y los límites de los derechos fundamentales, desde el significado del principio de legalidad hasta la posible justificación de la desobediencia 
a la autoridad, desde el alcance de la libre iniciativa económica hasta la función social de la propiedad.

Por último, sosteníamos que la filosofía del derecho tiene un valor teórico incluso cuando se dedica a especular o reflexionar sobre el derecho desde un punto de vista sustantivo y trascendiendo los aspectos puramente formales o lingüísticos, que son los que tradicionalmente han sido el objeto de lo que se ha dado en llamar convencionalmente una "teoría general del derecho" o simplemente "teoría del derecho". Que la filosofía del derecho tiene un valor teórico significa que ordena y explica la experiencia dotando de precisión y consistencia a los enunciados sobre la realidad jurídica: de precisión haciendo que los enunciados sean claros y distintos, como quería Descartes, y de consistencia haciendo que sean compatibles y coherentes entre ellos mismos y entre ellos y la realidad que intentan expresar. En este sentido, la filosofía jurídica no es una especulación arbitraria, decíamos, sino que procede teniendo en cuenta la lógica y la experiencia: la experiencia de lo justo tanto como la experiencia de lo legal, la experiencia de lo moral tanto como la experiencia de lo social y de lo político. Pero reconociendo que, al ser subjetivas muchas de estas experiencias (como vivencias que son, a diferencia de la experiencia de las ciencias empíricas) y por tanto, con frecuencia, difíciles de compartir por todo el mundo, la filosofía del derecho tiene mucho de relatividad y de provisionalidad. Mucho más cuando se trata de pensar sobre principios y valores morales, de los que, en contra de algunos planteamientos denominados "cognitivistas", se ha dicho que no son susceptibles de conocimiento, sino decidibles por la voluntad, por una voluntad motivada por el sentimiento, el carácter y los afectos. ¿Significa esto que la filosofía del derecho está afectada por la pasión y adolece inevitablemente de un carácter retórico o ideológico que la rebajan a una eterna conversación en la que todo vale, todas las opiniones son aceptables y todos los puntos de vista pueden reclamar la autoridad basada en el hecho de su formulación?

A lo que dijimos en el texto publicado antes debemos añadir ahora esto: que la relatividad y la provisionalidad de la filosofía jurídica no equivalen forzosamente a irracionalidad. La filosofía del derecho, como toda teoría, construye su discurso a partir de una posición personal y social determinada, pero ello no significa que todo enunciado tenga el mismo valor o sea igualmente atribuible a un sujeto -individual o colectivo- parcial y egoístamente interesado. Lo que puede garantizar la objetividad del discurso teórico es, por un lado, la consistencia interna, la capacidad explicativa de la realidad y la habilidad para adoptar el punto de vista del otro, escuchando sus argumentos y percibiendo su 
propia visión de las cosas. Eso es lo que permite distinguir entre lo que es un parecer desinformado y lo que es un juicio sólido, entre una opinión personal sin fundamentos y una afirmación respaldada por una teoría acreditada, entre la ideología puesta al servicio de intereses particulares y la crítica expresiva de intereses y valores susceptibles de un consenso universal. Puede que no haya valores de tal calibre, pero eso no echa por tierra la racionalidad: lo que hace racional el pensamiento es la posibilidad de argumentar, la posibilidad de dar razones y de resistir y superar las razones de los otros.

Pues bien, sirva esto como prólogo o introducción a la pregunta ¿qué filosofía del derecho merece la pena cultivar? Después de lo dicho, es obvio que no hay un único modelo de filosofía jurídica. La cuestión no es solamente que se pueden enunciar y mantener opiniones divergentes sobre una misma realidad, sino que, más allá de las opiniones singulares, es posible formular y construir marcos teóricos diferentes que sirven para estructurar y fundamentar, de manera diferente, los enunciados sobre esa realidad. En el campo de la filosofía del derecho, es posible distinguir, de manera aproximada, algunos de esos marcos. Éstos no constituyen paradigmas bien definidos, sino más bien aproximaciones o planteamientos complejos, diferenciados cada uno de ellos en distintas versiones que pueden ser más o me- nos rigurosas y consistentes. Simplificando al máximo, podríamos decir que hay un planteamiento iusnaturalista, un planteamiento positivista, y un planteamiento crítico.

Estos distintos planteamientos filosófico-jurídicos tienen en común el hecho de que pretenden ofrecer, del conjunto de objetos que forman parte de la experiencia jurídica, una versión o interpretación última y generalizadora, como es característico de la filosofía. Última en el sentido de que buscan una explicación de la realidad jurídica en sus aspectos más profundos, y no se detienen en la inmediatez de una descripción de las normas e instituciones jurídicamente relevantes. Generalizadora en el sentido de que toman como objeto de investigación predominantemente los aspectos más generales del derecho o de los fenómenos jurídicos, los que no son abordados por las ciencias jurídicas particulares o dogmáticas; o también en el sentido de que, estudiando los aspectos más concretos y singulares del derecho, los remiten a categorías generales que son las que proporcionan las referencias de sentido imprescindibles para su más pleno conocimiento.

Ahora bien, los distintos planteamientos filosófico-jurídicos abordan este tipo de cuestiones de forma netamente diferente. El modelo iusnaturalista tiende a percibir el derecho, y todos los fenómenos relacionados con él, desde el punto de vista de la moralidad, vinculando inescindible- 
mente el derecho con la ética, y defendiendo una concepción objetiva de la justicia y demás valores jurídicos, a los que hace residir, en último término, en la naturaleza misma del hombre. Una naturaleza, por otro lado, que no se reduce a los datos aportados por las ciencias naturales o empíricas, sino que viene interpretada o construida en una $u$ otra versión de lo que es esencial o auténticamente constitutivo de lo humano. Dentro de este modelo hay unas versiones más objetivistas y otras que lo son menos, pero todas ellas tienden a establecer una conexión necesaria entre el derecho y la moral, y consiguientemente afirman que la validez y obligatoriedad del derecho depende en última instancia de su contenido de justicia. Según esto, el derecho tendría una existencia ideal, y los sistemas jurídicos históricos sólo serían derecho en cuanto participasen de las características idealmente atribuidas a este concepto. Además, es ésta una reflexión sobre el derecho, sobre la justicia y sobre la naturaleza humana que tiene un carácter metafísico, entendiendo por tal aquel tipo de reflexión que no se limita a formular enunciados susceptibles de verificación o falsación empírica, sino que transciende la experiencia estricta a la búsqueda de verdades justificables racionalmente a partir de lo que se supone que son axiomas evidentes y argumentos generalmente convincentes.

El modelo positivista de filosofía del derecho parte, en cambio, de un postulado contrario a los presupuestos básicos del modelo iusnaturalista. Tal postulado reza así: no hay una conexión necesaria entre el derecho y la moral, y es, por tanto, indiferente para la validez del derecho que su contenido sea calificado como justo o injusto. La filosofía del derecho de carácter positivista se atiene estrictamente a la experiencia jurídica, y aborda sólo los problemas que pueden ser planteados a partir de tal experiencia y resueltos con las formas de reflexión circunscritas por ella. La experiencia jurídica está constituida por el derecho efectivamente vigente, y los análisis que el positivismo hace de ella están restringidos por el principio de neutralidad político-moral, que es lo que permite, según sus partidarios, mantener la pretendida limpieza o asepsia científica. El derecho es lo que es, no lo que debe ser, y sólo sobre lo que es se puede dar un discurso científico o racional. Lo que se diga sobre el deber-ser, sobre la justicia y sobre los valores estará siempre basado en preferencias subjetivas, y gozará, por tanto, de una validez sólo relativa a aquellos que mantienen tales preferencias. Lo que es -el derecho realmente existentese puede estudiar en dos aspectos: contenido y forma, y del enfoque de la reflexión en cada uno de ellos resultará una filosofía del derecho más empírica ("realista”, sociológica, economicista, psicologicista...), o una filosofía del derecho más formalis- 
ta (que acota como tema de estudio y análisis los aspectos lógicos y lingüísticos de la norma y del sistema de normas jurídicas).

Estos dos planteamientos (iusnaturalista y positivista) son diferentes y opuestos entre sí. Uno es normativo, el otro descriptivo. Uno presta atención a lo que debe ser, el otro a lo que es. Uno formula postulados, el otro refleja únicamente datos. Pero no son complementarios en sus diferencias, sino contradictorios. Se excluyen mutuamente en la medida en que cada uno de ellos parte de axiomas que son incompatibles y que no pueden mantenerse simultáneamente. En un caso se afirma: el derecho es lo justo, y lo justo puede ser conocido o determinado racionalmente; el derecho históricamente vigente está subordinado, en su pretensión de validez, a los valores de justicia que vienen dados con la misma naturaleza humana. En otro caso, en cambio (en el caso del positivismo jurídico), se rechazan estas tesis y se sustituyen por otras como las siguientes: el derecho es mandato coactivo, una manifestación de la fuerza y del poder políticamente organizado que tiene un carácter esencialmente histórico y, por tanto, sólo puede ser explicado y reconstruido racionalmente en cuanto tal manifestación histórica; no es preciso referir este derecho a los valores de justicia inherentes a la naturaleza humana, pues la validez o vinculatoriedad del derecho puede ser reconocida como algo histórica- mente contingente, independientemente del valor moral que se le quiera adscribir a ese derecho.

Ambos son, por tanto, paradigmas diferentes que establecen en cada caso un marco para la investigación filosófico-jurídica, y asignan los límites de lo que tiene sentido plantear como problema racionalmente resoluble. Hay algunos temas cuyo análisis se solapa en parte por ambos planteamientos, pero el sentido último y las respuestas finales que ambos ofrecen son, indudablemente, divergentes. Conceptos controvertidos como el de derecho subjetivo, obligación jurídica, validez, fuentes del derecho, origen y función del derecho, incluso norma y ordenamiento jurídico..., adquieren connotaciones diferentes según el planteamiento filosófico-jurídico que se adopte. Si en una primera aproximación esas diferencias no son perceptibles; lo serán cuando la argumentación es seguida hasta encontrar las respuestas últimas dentro de cada uno de los respectivos discursos.

Pues bien, se puede afirmar que si el planteamiento iusnaturalista de la filosofía del derecho representa la tesis, y el positivista la antítesis, la filosofía o teoría crítica del derecho puede concebirse como una síntesis superadora de ambas. Bien entendido que en dicha síntesis no quedan incólumes los anteriores planteamientos, sino que, como en todo proceso dialéctico, los contrarios son suprimidos y conservados al mismo 
tiempo, elevados a un nuevo nivel en el que aparecen modificados en relación con la forma que tenían anteriormente. La síntesis no es una agregación, ni se configura como un complemento mutuo de los elementos a partir de los cuales surge. Es una nueva construcción que supera los planteamientos anteriores. Veámoslo más de cerca.

1) La teoría crítica del derecho parte de la constatación de que el derecho es un fenómeno histórico, y concretamente la manifestación de una voluntad políticamente organizada. El derecho asume distintas formas y distintos contenidos según las circunstancias, históricamente variables, en las que surge y evoluciona. Es un dato concreto de la experiencia. Las formas y contenidos del derecho en una sociedad y en un momento histórico es lo que constituye propiamente el objeto de reflexión para la filosofía jurídica de intención crítica. El derecho responde a determinados factores causales y realiza determinadas funciones sociales. Por tanto, de lo que se trata es de estudiar el derecho en cuanto elemento condicionado y condicionante de la realidad social, de estudiar la relación entre las normas y la realidad social que circunscribe esas normas.

2) No obstante, hay una conexión (conceptual) necesaria entre el derecho y la moral. Aunque siempre aparece como un producto histórico, el derecho pretende ser justo. Es una manifestación del poder, pero lleva siempre inherente una pretensión de legitimidad. No siempre consigue realizar esa pretensión a juicio de todos sus destinatarios: no siempre basta la legalidad para colmar las pretensiones de legitimidad. En este sentido, la falta de legitimidad equivale a un fracaso moral, a una frustración del objetivo inicialmente pretendido.

3) La especificidad del discurso crítico surge de la disparidad entre eso que ha sido inicialmente pretendido (la legitimidad) y lo efectivamente realizado, entre el postulado y el dato, entre la apariencia y la verdadera realidad. La crítica es análisis y denuncia de una contradicción, de una contradicción que se hace evidente al comparar la norma con la realidad social de su origen y de su funcionamiento.

Éstas serían las tesis básicas de la filosofía o teoría crítica del derecho, expuestas de modo sucinto, de manera comparativa con las de los planteamientos iusnaturalista y iuspositivista. Ahora bien, también la filosofía jurídica iusnaturalista se distingue por la denuncia que hace del derecho existente, cuando lo percibe como algo defectuoso y mejorable. ¿Qué es lo que convierte el iusnaturalismo en un discurso propia y específicamente crítico? Digamos que lo que hace del iusnaturalismo, que es un planteamiento idealista, un discurso crítico es el análisis social, el análisis de los orígenes y de 
las funciones y efectos del derecho. La crítica no es una simple denuncia basada en la mera lectura de los textos jurídicos, realizada al constatar en ellos un contenido manifiestamente recusable por contradecir valores que se supone que son incuestionables. Es más bien la denuncia que se lleva a cabo como resultado de poner de manifiesto funciones o efectos latentes e indeseables del derecho, funciones o efectos cuya relación con el derecho estaba oculta y sólo se ha hecho patente y perceptible cuando se ha logrado restaurarla reflexivamente mediante una mirada "interesada".

La crítica del derecho, en este sentido, es crítica del derecho como ideología, crítica del carácter ideológico que a veces asume el derecho y que la reflexión consigue desvelar al poner de relieve la complejidad de sus conexiones no manifiestas con la realidad social. La pretensión de universalidad del derecho queda falsada o desmentida al referirlo a la totalidad social de la que forma parte, o bien a otros elementos de esa totalidad con los que mantiene una relación específica y que le confieren su verdadero sentido (el poder, la economía, la cultura). Así, por ejemplo, el derecho puede aparecer como una garantía de igual acceso al poder, que permite a todos los individuos y los grupos organizarse para defender sus intereses y utilizar los resortes necesarios para la toma de decisiones, y sin embargo la crítica puede revelar cuáles son los mecanismos que obstaculizan o impiden dicho acceso a determinados individuos o grupos; o puede aparecer como un instrumento de distribución equitativa de recursos en atención a las necesidades o los méritos de cada cual, y en la realidad resultar, mediante el análisis crítico, que favorece sistemáticamente a los que poseen unas condiciones u ocupan una posición que no tiene nada que ver con sus necesidades o sus méritos; o, en definitiva, puede aparecer como el reflejo de valores compartidos y asumidos por todos los ciudadanos, y demostrarse que, imponiendo el respeto de tales valores, el derecho perpetúa un sistema social discriminatorio o excluyente por su carácter racista, xenófobo o sexista.

La crítica del derecho, por tanto, no es una reflexión sobre el derecho en lo que éste tiene de jurídico, sino que transciende el derecho en cuanto norma para estudiarlo en cuanto objeto jurídico y social a la vez. Todo lo contrario de lo que propugnaba Hans Kelsen para su teoría pura del derecho (una versión canónica del positivismo jurídico), en la que el "principio de imputación" acota el discurso jurídico frente al "principio de causalidad", que enmarca otro tipo de ciencias distintas de la ciencia del derecho.

También podría hacer esto, sin embargo, un positivismo de carácter sociológico. ¿Cómo distinguir la crítica del derecho de esa sociología 
jurídica que se propone la reconstrucción de la relación de causalidad que mantiene el derecho con la sociedad? Pues bien: la crítica del derecho es sociología jurídica, pero se distingue del positivismo por su intención práctica en el sentido fuerte de la palabra: por su intención de promover y contribuir, con sus análisis, a la reforma y al cambio social en favor de un mundo más justo.

La crítica no es moralmente aséptica, sino que toma partido de manera interesada. No se limita a describir o a explicar intentando mantener ese prurito de neutralidad o cientificidad que caracteriza a los planteamientos positivistas. La crítica está dirigida por un interés moralmente cualificado (universalizable, como todo interés moralmente legítimo). Pero esa toma de partido no es ningún obstáculo para la objetividad de sus enunciados mientras éstos sean enunciados sobre una realidad constatable por procedimientos intersubjetivamente compartidos. Puede que el interés que dirige la investigación no sea compartido de hecho por muchos, pero eso no afectará a la objetividad o racionalidad del discurso crítico mientras mantenga la fidelidad a las constricciones metodológicas impuestas por el pensamiento científico.

En realidad, la crítica del derecho es una modalidad de la filosofía jurídica, pero también puede cualificar o caracterizar a la ciencia del derecho. La distinción entre filosofía y cien- cia no tiene mucho sentido desde el punto de vista de la crítica. Por su grado de abstracción podrá estar más próxima a lo que tradicional o convencionalmente se entiende como reflexión filosófica sobre el derecho (cuando versa sobre sistemas jurídicos, o sobre conceptos o categorías jurídicas generales) o, al contrario, podrá acercarse más al discurso propio de las ciencias jurídicas específicas (cuando versa sobre instituciones, normas o prácticas jurídicas concretas). La crítica del derecho, en cualquier caso, intentará desvelar la falsa apariencia del derecho, su fracasada pretensión de legitimidad, con la mirada puesta en su reforma.

El punto de vista de la crítica, el principio moral que la anima, puede estar reflejado, aunque sólo sea de manera abstracta o fragmentaria, en el sistema jurídico criticado (por ejemplo, en las normas y principios constitucionales), o bien puede estar dirigido contra dichas normas y principios por considerar que su mantenimiento y su observancia da lugar a conductas o relaciones sociales inaceptables. En este sentido, la crítica puede ser interna o externa, según se apoye en un punto de vista aceptado por el sistema, o bien ajeno y transcendente a él. En cualquier caso siempre será crítica del derecho como ideología, es decir, desvelamiento de efectos y funciones no reconocidos expresamente por el derecho, y legitimados implícitamente por él.

Así, cuando la crítica denuncia la 
inconstitucionalidad de algún instituto legal o de alguna norma, adopta un punto de vista interno. Cuando denuncia la injusticia provocada por algún principio constitucional (como tará siempre confrontar el derecho con las pretensiones de legitimidad que le son inherentes. En esto consiste su especificidad y esto es lo que podrían ser los que afectan a la consle confiere un valor añadido en todo titución del sistema económico, a la estructura del Estado o a la organización de las relaciones familiares), entonces adopta un punto de vista lugar y en todo momento, ya que el derecho se suele plegar, demasiado a menudo, a los deseos e intereses del poder con la retórica de la justicia. 